had the patients untied; but if very delirious, they were tied up again. Witness did not get enough of milk and could not drink the beef-tea. One pint of the milk in the 24 hours was all he got. The broth or beef-tea at dinner he could not" tackle." If he went to sleep in the night, he found on waking that his milk had been consumed by others. When convalescent he acted as nurse, and had extra meat, of which he was very glad, tough and flavourless though it was. Fourteen patients once refused to eat the dinner until Mr. Kynaston had seen the meat. The beds and sheets he described as they have already been; while poultices and other appliances ordered by the doctors were withheld. In his own case, a mustard poultice ordered at 10 A.M. was not given till 7 P.M. A man, Holmes, he said, died through neglect, and into his bed, filthy as it was, a patient named Hatcham was put. Cross-examined by $\mathrm{Mr}$. Williams, he admitted that when he left the hospital he did not complain to Dr. Grieve. In answer to the Chief Commissioner, he said he came out of hospital with fourteen wounds upon him. Questioned by Dr. Buchanan, he stated that the wounds were boils due to poverty of living. During his residence in Wards 6 and 11 , more than five patients died; but he never saw one of the assistant medical officers pay a visit between 11 p.Mr. and the morning visit. The doctor had given them up as in a "low state," from which witness thought they might have been "livened up" by better diet. The nurses were too few; and the man Holmes, though in need of nursing and feeding, could not be approached-" he smelt so." "The food was put at his side, but he could not help himself. Witness had sometimes fed him. The nurses had too much to do.-The next witness called was Elizabeth Fowler, whose depositions turned chiefly on the conduct of the nurses, but contributed little to what had already been stated in evidence.

On Wednesday, depositions bearing on the tying-down of patients, the insufficiency and badness of the milk and beeftea, the dirtiness of the sheets and towels, and the vermin on the convalescents' clothes were made by the witness Ellistie, who admitted in cross-examination that he had made no complaint of the treatment to the friends who visited him at the hospital.-Tidbury, the next witness, gave similar evidence, dwelling particularly on the watering of the milk, the ill-regulated bath-rooms, and the wet state of the floors and passages, from which he caught a violent cold, being unprovided with shoes or stockings. $\mathrm{He}$ also deposed to nurse Donaldson drinking the whisky and wine of the patients who were too ill to notice it. Further evidence was given by him as to the state of the huts erected in the ground of the hospital for convalescents. In reply to Dr. Buchanan, who said they were as good temporary wards as he had seen, witness said the wind came in strong enough to blow the hair off one's head. Cross-examined by Mr. Williams : Witness had seen nurse Donaldson drunk four or five times, but did not complain to Mr. Greaves. As to the bread, it was neither good nor plentiful; and as for the butter, he would not grease a cart-wheel with it.-Wilson, the next witness, deposed to the dampness of the nightgowns, the bad quality of the beef-tea, the shortness of the milk; and generally corroborated what had been said by previous witnesses; adding that he, like the rest, was afraid to complain lest the beer should be stopped.-Partridge, another witness, had to stand naked three-quarters of an hour in the receiving-ward, owing to the shirt given him being so damp he could not put it on. He corroborated, in cross-examination, the general complaints as to the milk, the beef-tea, the bedding, the towels, and the vermin.Benyon, another witness, deposed as to the dampness of the night-gowns, the tying-down, and the delay in removing dead bodies. The huts, he said, were loathsome with filth and vermin. Cross-examined by Dr. Buchanan, he did not remember the instance of a ward being left without a nurse; and in answer to the Medical Commissioner, he stated that he never saw a patient washed by a nurse, nor was the discharge from the skin attended to in any way; but that he considered the patients fairly taken care of during the day. In reply to Dr. Buchanan, witness stated that an hour and a half was sufficient for the nurses to do their work in; that he never saw wine or whisky in the ward and that a man in the bed next to him was ordered whisky, but did not get it.

On Thursday Mr. Henley (inspector) stated that the admission-book of the hospital should be produced, but not taken away. 'The inspector seriously appealed to Mr. Collins against over-laying the trial with evidence. The inquiry was not a special one, but ordered in the usual way by the Local Government Board, calling upon their inspectors, not special commissioners, to inquire into the charges brought by the assistant medical officers against the managers and superintendents of the Hampstead Hospital. They put it to Mrr. Collins whether, since the examination of Mr. Aikman, the case should have been carried any further. Most of the evidence was mere repetition; and though it certainly proved the extent of the dissatisfaction, it must be remembered that the hospital had been established at a great emergency, and many benevolent ladies who had been concerned in its management would not allow the evidence to go unchallenged. After this intimation, he hoped Mr. Collins would not compel them to refuse evidence as irre. levant. The veracity of the assistant medical officers, just commencing life, had been called in question; and, therefore, a latitude of examination must be allowed. At the same time, when those gentlemen left the hospital they ceased to be connected with the Metropolis Local Management Board, and so passed beyond the notice of the inspectors. The inquiry was really a private one, the public having no right to be present, and the reporters being admitted only that the newspapers might have every information. If Mr. Collins persevered in bringing in more evidence it would be for the inspectors to consider what course to adopt.

Mr. Collins said that after a little mcre evidence he would call the medical witnesses.

The next witness, Bryant then deposed to the grievances already stated ad nauseam. Cross-examined by Mr. Williams, he said they tied a delirious man down with three sheets and a strait-waistcoat.-Miss Kate Black was the next witness, who made depositions similar to the mass of those already made public. Personal cliastisement was inflicted upon patients by the nurses, one of whom, when asked by a female patient to be kind to her as she would not live long, said, "No! old gal, you'll be off to-morrow"; and, sure enough, the next day the woman died. Two other ex-patients were then examined, and, when their depositions (similar to the majority) were taken, the court adjourned. The next evidence will be the medical.

\section{THE SOUTHAMPTON GUARDIANS.}

To the Editor of THE LANCET.

Sir,-At a special meeting of the Southampton Medical Society hold at Dr. Trend's on Tuesday, September 19th, to consider what steps should be taken with regard to the recent election of a homœopath by the Southampton Board of Guardians, it was unanimously resolved to memorialise the Local Government Board on the subject. Enclosed is a copy of the memorial which was forwarded, and it will be esteemed a favour if you will kindly give it a place in the columns of The LANCET.

I am, Sir, your obedient servant,

Southampton, Oct. 3rd, 1871.

W. SIMs.

"To the Right Honourable the President of the Local Government Board.

"The members of the Southampton Medical Society, having had their attention drawn to the recent appointment by the Southampton Board of Guardians of a homoepathic practitioner as medical officer of No. 2 district of the Southampton Incorporation, beg to express to the Local Government Board the deep regret with which they view this appointment. They do so, however, not on grounds of a personal nature with respect to the gentleman appointed, but solely from a feeling that homoopathy is not entitled to rank as a rational system of medicine, which opinion is shared by all the medical authorities of this country, including the various examining boards legally empowered to grant licences to practise medicine, the medical staffs of all our large hospitals both in London and the provinces, and the medical departments of the army and navy.

"Assuming that the officer elected will treat his patients on the principles of homoopathy, this appointment virtually hands over the sick poor of the district to a system of medicine unrecognised by the profession at large; de- 
prives them, in cases of difficulty and danger, of the assistance of regular practitioners, from the impossibility of these appearing in any way to sanction what they believe to be so unsound in principle; and will be the occasion of much suffering and distress in cases where a medical man requires and should have assistance from his medical brethren.

"This appointment is, moreover, directly opposed to a Minute of the late Poor-law Board, in which they refuse to sanction the appointment of homcopathists as Poor-law medical officers.

"Under these circumstances, this Society begs respectfully to urge on the Local Government Board the propriety of withholding their sanction from the authoritative introduction amongst the poor of the practice of medicine based on the principles in question.

"Signed on behalf of the Southampton Medical Society: "J. R. WARE, M.R.C.S. \&c., President. W. StMrs, M.B., T. Broster, M.D. $\}$ Hon. Secs.

"Southampton, Sept. 23rd, 1871."

\section{bitinatu.}

DR. GEORGE C. BLACKMAN,

PROFESSOR OF SURGERY IN THE MEDICAL COLLEGE OF OHIO, U.S.

Dr. George C. Buachman died on Wednesday, July 19, aged fifty-two. He was the second son of Judge Thomas Blackman, and was born at Newtown, Connecticut, in 1819. He graduated in medicine at the College of Physicians and Surgeons, New York, in 1840. For a time he was engaged in practice in New York City, and in Newbury, and then as surgeon to a packet-ship, in which capacity he crossed the Atlantic sixteen times. $\mathrm{He}$ also visited London and Paris in order to pursue his professional studies. We are told that upon his first visit to London he possessed but seventy-fivedollars; and on this sum he managed to live for some months. How patiently and heroically he struggled against the many privations he had to endure was known but to few; but his enthusiastic love of surgery made every other consideration of secondary importance. He was most constant in his attendance at many of the metropolitan hospitals, but especially at King's College -and St. George's, where his intelligence, eager desire for information, and courteous manners, gained him a general welcome and secured him many friends. In 1855 Dr. Blackman was elected to the Chair of Surgery in the Medical College of Ohio. Prior to this he had edited the last edition of "Mott's Velpeau," and translated, with annotations, "Vidal on Venereal Diseases." Almost from his entrance into the profession he was a contributor to medical journals.

In 1847 he was elected a fellow of the Royal Medical and Chirurgical Society-"an honour," it is stated in the American Practitioner, "which, at that time, and for some years subsequently, we believe, no other American had received." Professor Gross was so highly impressed with Blackman's powers and abilities that, in urging him to settle in the West, he wrote, telling him that "an empire in surgery was awaiting him"; and a friend kindly adds, " he went, took possession of the empire, and proved his imperial power."

Dr. Blackman is said to have excelled in surgical diagnosis; and, as an operator, to have ranked among the greatest of his countrymen; and, from what we know of American surgeons, it may truly be said no higher rank, in this respect, could be coveted by any. He is reported, as a student, to have evinced his love for operating by successfully practising on some cases of talipes with a tendon knife fashioned from a scalpel by the "village blacksmith."

As a teacher, Blackman was accurate, clear, and impressive, essentially practical from his great experience, and full of information from his extensive reading. His private surgical library is reported to have been one of the finest in the United States, and will probably be secured by the profession of Cincinnati for their city library. A not long illness terminated in dropsy, from disease of the liver, and this promising surgeon was cut off prematurely at the age of fifty-two, when his experience and success were commencing to be equally and abundantly useful to his fellows and to the institution to which he was attached.

We regret to learn that one who had so struggled with the caprices of fortune in his early life, and had apparently successfully battled against them, as far as his professional reputation and position were concerned, has died poor, and left a widow and children without adequate provision for their support. It is proposed by his friends in the United States to raise a subscription in their behalf, and we most cordially wish the proposal every success, in respect for the memory of one so generous and genial as a friend, so thorough and honest as a man, so practical and expert as a surgeon.

JOHN WILLIAM IRVINE, M.D., L.R.C.S., L.S.A.

Tris gentleman was the eldest son of Dr. James Pearson Irvine, who for a quarter of a century practised his profession in Lancaster. He was educated at the Lancaster Royal Grammar School, and afterwards at the University of Glasgow, where his distinguished career, in anatomy especially, led to his appointment as Curator of the Leeds School of Medicine, at which place he finished his medical studies. He obtained his diplomas of L.R.C.S. Edin. and L.S.A. Lond. in 1859, and in 1862 became a Doctor of Medicine at St. Andrews, passing his examination with high honours.

His success in Liverpool, where he commenced practice, was rapid. He was at once appointed Honorary Surgeon to the Liverpool Caledonian Schools, and subsequently to the Liverpool Dispensaries. In 1864 he was elected Visiting Surgeon to the West Derby Union Hospital, where he had excellent opportunities for pursuing the surgical branch of his profession, to which he always had a strong inclination. All these appointments he held up to the time of his death, doing his duty diligently and winning the esteem of allpatients or others-with whom his position brought him in contact. He was also an assistant surgeon to the 1st Lancashire Rifle Volunteers, where his loss is particularly felt by officers and men.

By gentlemanly bearing and scholarly attainments, Dr. Irvine had won the confidence of all who knew him, and had gained that position which great qualities in those practising medicine deserve. His affable and genial manners attracted the suffering poor in his wards, and his visits were like gleams of sunshine to them. With a kind and willing ear for all, he won from suffering humanity a love which is better than any stone man can raise over the grave, and left on the hearts of his fellows a better epitaph than pen can write. As regards his more immediate connexion with his brother practitioners, it may truly be said that there is none who knew him but will lament his untimely death.

He shone chiefly as a surgeon, and as a surgeon, operative or otherwise, he gave unmistakable signs of becoming one of the leaders in the town in which he practised. He contributed several essays to the medical papers, one on "Fever in Liverpool," in the Medical Times and Gazette, another on "Resection of the Clavicle with formation of the entire bone," in the pages of THE LANCET. At the time when his illness overtook him he was engaged on a paper for the "Liverpool Medical and Surgical Reports," on Amputation of the Hip-joint, that paper being the result of three successful hip-joint amputations after failure of resection of the knee-joint and for disease of the femur.

The unfortunate gentleman last spring suffered from an attack of relapsing fever, which attack was probably favoured by his unremitting labours at the fever wards of the West Derby Hospital during the fever and small-pox epidemics. He never thoroughly recovered his strength after this attack, though he still supervised the wards of his hospital, with but short intermissions. In the beginning of August last, by the strong advice of his medical friends, he was induced to undertake a voyage to Canada, on board the steamship Germany. He suffered from severe sickness on the second day, which prostrated him so much that, on the fourth day after leaving Liverpool, he died 